\title{
Forschungen zur Politik Karls V. während des Augsburger Reichstags von 1530.
}

\author{
Von Eduard Wilhelm Majer.
}

I.

\section{Krieg oder Konzil? \\ Vorbereitende Unterhandlungen.}

Im Fruhjahr des Jahres 1530 betrat Karl V. nach neunjähriger Abwesenheit wieder dentschen Boden, mit dem Willen, der religiösen Spaltang im Reich ein Ende za machen. Statt dessen finden wir am Schlab des Jahres den Protestantismus dogmatisch und politisch gefestigt. Trotzdem die Ansgleichsverhandlungen in Augsburg gescheitert waren, unterlieB Karl energische MaBregeln zur Erhaltung der alten kirchlichen und staatlichen Mächte. Vom Standpankt des Katholizismus und des römisch-deutschen Kaisertums ist dieser Verzicht auf eine kriegerische Anseinandersetzong mit den Protestanten zweifellos als eine versäumte Gelegenheit za bezeichnen. $\mathrm{DaB}$ der Krieg um 16 Jahre aufgeschoben warde, hat eine wirkliche Unterwerfung der Protestanten, die 1530 noch nicht als völlig ausgeschlossen erscheint, unmöglich gemacht. In diesen 16 Jahren hat der Protestantismus an Kraft gewonnen, und nur mit Hilfe protestantischer Fursten hat der Kaiser 1546/47 den Schmalkaldischen Bund anfs Haupt zu schlagen vermocht. 1530 hätte er die Latheraner viel leichter niederzwingen können ${ }^{1}$ ).

1) 0. Winkelmann, Der Schmalkaldische Bund 1530-1532 und der Nürnberger Religionsfriede. Straßburg 1892. S. 2: "Mit einigen raschen Schlägen hätte er ihren Widerstand leicht brechen können." 
Es ist oft dargestellt worden, welche Faktoren damals hemmend wirkten auf die kriegerische Energie Karls V.: er war noch keineswegs im festen Besitz der Vormacht in Italien, deren Sicherang seine militärischen und finanziellen Kräfte vor allem in Ansprach nahm; von Franz I. hatte er ebenso einen Angriff zu befurchten wie ron den Tttrken; schlieblich war anf die Reichsfursten, die dem alten Glauben treu geblieben waren, fur ihn kein Verlaß. Trotzdem wird man sagen können: wäre in Karl der Glanbenseifer und der Fanatismus der Gegenreformation mächtig gewesen, er hätte auch unter diesen schwierigen Verbältnissen das Schwert in die Wagschale geworfen, andere Interessen dieser einen Aufgabe geopfert.

Aber Karls V. Politik warde in einem anderen Geiste geftubrt; er war ein zu kubler Rechner, am sich ganz in den Dienst einer Ecclesia militans zu stellen. Er war auch nicht blind fur die schweren Mängel, die dem bestehendeu Kirchenwesen anhafteten. Eine kaiserliche Reform der Kirche schwebte ihm vor Angen. Bei dieser Gesinnang fiel es ihm nicht schwer, am der gutlichen Verständigung willen den Wunschen der Deutschen nach einem Konzil entgegenzakommen. Die Konzilspolitik war zanächst ein Zeichen seiner friedlichen Bestrebungen and schien eiue Kriegspolitik vielfach anszaschließen. Wir werden ans den Verhandlungen im Jabre 1536 erseben, daß der Konzilsplan immer dann eine Nenbelebung erfuhr, wenn eine Verständigung mit den Protestanten möglich schien oder wenn der Kaiser zur Einsicht kam, da $b$ er einer kriegerischen Lösung des Konflikts nicht gewachsen war.

Über die Motive und die Wendungen dieser Politik, die nicht eine zielbewaßte Fuhrung bot, sondern vorsichtig das Gelände abtastete, um den gangbarsten Weg ausfindig za machen, sind widersprechende Äuberungen gefallen. Katho= lische Apologetik hat die unbedingte Friedfertigkeit des Kaisers za erweisen sich bemtlht ${ }^{1}$ ). R a n k e hat die Auffassung begründet, nach der Karl V. wohl friedlichen Mitteln den Vor-

1) C. B. Hefele-Hergenröther, Konziliengeschichte Bd. 9. Freiburg 1890. S.746: „Karl dachte nicht daran, gewaltsame MaBregeln gegen die Latheraner in Anwendung zu bringen oder vorzubereiten." Vgl. weiterhin Psstor. 
zug gegeben, aber die Anwendung von Gewalt sich rorgenommen habe fur des Fall, daB die Verhandlungen nicht zam Ziele fubren sollten ${ }^{1}$ ). M a a re nbrecher, der diese beiden Tendenzen der kaiserlichen Politik am schärfoten herausgearbeitet hat, entbält sich des Urteils, was „wirklich Karls geheimer Gedanke" gewesen sei ${ }^{2}$ ). Pastor, der fruher jegliche kriegerische Absicht des Kaisers lengnete ${ }^{8}$ ), nimmt sie neuerdings futr einen beschränkten Zeitranm im Oktober 1530 als vorhanden an ). Hierin lolgt er Bemerkangen ron Eho es ${ }^{5}$ ).

Gerade die Veröffentlichnng der noch unbekannten Berichte des päpstlichen Legaten Campegio dorch Eh se 8 ${ }^{6}$ ) wirft neues Licht anf die Politik des Kaisers. Ich kombiniere diese Berichte mit Stucken der kaiserlichen Korrespondenz aus dem Archiv von Simancas, die ich als Beilagen gebe. Sie entstammen einer Sammlung sehr sorgfältig hergestellter Abschriften, die Herr Dr. J o sef Schwe i z e r im Auftrag des Kónigl. PreuBischen Historischen Instituts zu Rom in Simancas angefertigt hat.

Karl V. hatte im Winter 1529/30 während der Zusammenkunft zu Bologna vom Papst die Zusichernng des Konzils

1) Sämtliche Werke Bd. 3, S. 164.

2) Geschichte der katholischen Reformation. Bd. 1 (Nördlingen 1880) S. 312. Vgl. Karl V. und die dentechen Protestanten 1545-1555. Dtisseldorf 1865. S. 26: „Wenn so am Ende des Jahres 1530 die große Frage, ob ein Konzil oder ein Krieg oder beides zugleich die deutsche Reformation bändigen sollte, noch in der Schwebo gehalten warde, so konnte die Entscheidung in dieser Alternative für die kaiserliche Politik nur aus der gesamten Lage, aus der großen Anschauung aller politischen Verhăltnisse von Enropa erfolgen."

3) Die kirchlichen Reunionsbestrebungen. Freiburg i. B. 1879. S. 63.

4) Geschichte der Päpste. Bd. 4, Abt. 2. Freiburg 1907. S. 418.

b) Kardinal Lorenzo Campegio anf dem Reichstag von Augsburg 1530. In: Römische Quartalsschrift für christliche Altertumskunde und für Kirchengeschichte. Bd. 20 S. 67 Anm. 4.

9) Unter dem eben angeführten Titel in der genannten Zeitschrift; Bd. XVII 383-406; XVIII 358-384; XIX 129-152; XX 54-81; XXI 114-139 (von Bd. XIX ab haben die beiden Teile der Zeitschrift getrennte Paginierung). Über die Schreibnng Campegio (statt Campeggio oder Campegi) vgl. ebenda Bd. XIX 129. 
erwirkt fur den Fall, daB es sich als notwendig erweisen sollte; seinerseits versprach er, anf jede Weise die Ketzer zar alten Kirche zartickzufthren. Seine Zaversicht, daB dies ohne Gewaltmabregeln, bloß dorch seine persönliche Dazwischenkunft, möglich sein werde, spricht sich darin aus, $\mathrm{da} B$ er nur eine ganz geringe Trappenmacht - tansend Landsknechte ans dem Allgän - für sich aufbieten lie ${ }^{1}$ ). Offensichtlich tberschätzte er seine Autorität and seinen Einfla $B$ auf die Stïnde. In diesem Irrtam scheint er bestärkt worden za sein darch die Vorverhandlangen, die er zu Innsbrack mit einigen Fursten des Reichs und den Abgesandten anderer, daranter anch des sächsischen Kurfursten²) pflog. Er glaubte in Augsburg einen „gefälligen and dienstbereiten" Reichstag zu finden ${ }^{3}$ )!

Es fehlte nicht an skeptischen Stimmen. Miguel Mai, Karls Gesandter in Rom, riet ihm, der Tagung fernzableiben, weil die Furcbt vor seinem Kommen die Ketzer mehr schrecken wurde als seine Gegenwart, and weil ein Paktieren, das doch notwendig werden könnte, sich mit der Ehre des Kaisers nicht vertrige. DaB Konzessionen ratsam seien, habe er dem Papst schon za verstehen gegeben ${ }^{4}$ ).

Viel entschiedener and intransigeuter war die Sprache des päpstlichen Legaten Campegio. Es leidet keinen $\mathrm{Zweifel,}$ daB dieser energische Mann, der den Lutheranern den Kampf bis anfs Messer ansagte und sich doch der Notwendigkeit von Reformen nicht verschlob, am klarsten sah, was der Macht der katholischen Kirche nottat. Man wird sich aber huten mulssen, seine Ansicht mit der seines Auftraggebers Klemens VII. zu identifizieren und darf auch nicht annehmen, dab er die kaiserliche Politik ins Schlepptau genommen habe. Campegio hat am 8. oder 9. $\mathrm{Mai}^{\mathrm{b}}$ ) in Innsbruck anf des Kaisers Bitten jenes Gatachten uber das einzuschlagende

1) B au m garte n, Geschichte KarlsV. Bd. III. Strabburg 1892. S.31.

2) Vgl. jetzt $\nabla$. S ch habert, Beiträge zur evangelischen Bekenntmisund Bthdnisbildung 1529/30. Zeitschrift für Kirchengeschichte 30 (109) S. 316-35̃.

3) Karl V. (Covos) an Loaysa 14. Juni 1530. Beilage Nr. 2.

4) Bai an Covos 15. Mai 1530. Beilage Nr. 1.

s) Uber das Datum vgl. Ehses, Römische Quartalschrift XVII $387 \mathrm{f}$. Anm. 
Verfahren angefertigt, in dem er empfiehlt, "mit Feuer and Schwert"' gegen die Protestanten vorzagehen, falls sie hartnäckig bleiben sollten ${ }^{1}$ ). Er benatzte jede Gelegenheit, am diese Überzengung za vertreten, and seine Mahnungen blieben nicht ohne Eindrack auf die altglänbigen Fursten, die dem Kaiser nach Innsbrack entgegenkamen, und anf Karl V. selbst. Wenigstens trug Karl bei seinem ersten Auftreten in Augsburg demonstrativ das Bestreben zar Schau, die katholischen Interessen energisch za vertreten ${ }^{2}$ ). Absichtlich warde der Vorabend des Fronleichnamsfestes als Einzngstag gewählt and unter persönlicher Teilnahme des Kaisers am folgenden Tag die Prozession veranstaltet. Am 18. Juni erlieB er dann die Verordnung, daB in Augsbarg niemand predigen durfe, der von ihm nicht daza ermächtigt sei $^{8}$ ).

Der Kaiser hatte nun Gelegenheit, die unter den Reichsständen herrschenden Stimmungen aus eigener Anschanung kennen zu lernen. Nur wenige Fursten, wie Joachim von Brandenburg and Georg von Sachsen, wollten es auf einen Krieg ankommen lassen. Die Majorität war einer gewaltsamen Lösang des Konfliktes abgeneigt, teils aus politischen, teils aus religiös-kirchlichen Grunden; eine Steigerung der Kaisermacht, wie sie die Folge eines siegreichen Krieges sein muBte, war ihr nicht erwthnscht, und anter dem Einfluß erasmianischer Denkweisen wurde vielfach anerkannt, daß in der Kirche gar manches za bessern sei. Diese irenisch gesinnten Katholiken sahen, dab ein siegreicher Glaubenskrieg jede Reform unmöglich machen würde ${ }^{4}$ ). Wie die

1) Abgedruckt bei Maureabrecher, Karl $\nabla$. und die deutschen Protestanten $3 *-16 *$.

2) Diese Stimwung spricht noch aus den Berichten, die der Kaiser über die ersten Tage in Augsburg gibt. Karl V. an die Kaiserin 8. Juli (Simancas, Estado 635 fol. 83); abgedruckt bei Döllinger, Dokumente zur Geschichte Karls V., Philipps II. und ihrer Zeit. Regensburg 1862 S. 7; übersetzt bei Heine, Briefe an Kaiser Karl V. gescbrieben von seinem Beichtvater (Garcia de Loaysa) 1530-32 Berlin 1848. Mit diesem stimmt fast wörtlich uberein der Bericht im Brief an Miguel Mai 27. Juni (Simancas, Estado 1557 fol. 69-71). S. 399.

3) Über die Vorgeschichte dieses Verbots vgl. Schubert a. a. 0.

4) Vgl. Winkelmann a. a. O. S. 7. 
Protestanten forderten anch sie ein Kouzil, von dem sie freilich anderes erwarteten als jene.

Unter dem Druck der altglänbigen Stände ist der Kaiser noch entschiedener als bisher fur die Berufang des Konzils eingetreten. Aber die Alternative: Krieg oder Konzil hat er nie so eindentig entschieden wie die Mehrzahl der Altglänbigen.

Nachdem am 25. Juni die Augsburger Konfession der Lutheraner verlesen war, fabte der kaiserliche Rat uber das weitere Verfahren Beschlusse, die dem Legaten vorgelegt warden ${ }^{1}$ ). Drei Möglichkeiten wurden erörtert: 1. Die Protestanten unterwerfen sich dem Schiedsgericht des Kaisers, in dem die altglänbigen Fursten die katholische Sache gegen die Ketzer zu vertreten haben. 2. Wenn sie sich weigern, einen Richterspruch des Kaisers anzanehmen, wird ein allgemeines Konzil vorgeschlagen, unter der Bedingung, daB die Lutheraner bis zam Konzil ihre Nenerungen aufgeben and dab das Wormser Edikt beobachtet wird. Andererseits mussen Vorkehrangen gegen die Mißbränche in der Kirche getroffen werden, nicht nur, am die Protestanten leichter zn gewinnen, sondern anch um der Kirche selbst willen. Die Verhandlungen in der Glaubensfrage sind mit MäBigang zu fuhren, damit die Protestanten nicht verstockt werden. 3. Falls sie weder dem Kaiser noch dem Konzil eine bindende Entscheidung zuerkenned, muB mit angemessener Strenge vorgegangen werden. Der Legat möge selber angeben, in welcher Weise das bei der angenblicklichen Lage der Christenheit möglich sei, and wie uberhaupt za den Waffen gegriffen werden könne.

Es zeigte sich bald, daß die erste dieser Möglichkeiten nicht zn verwirklichen war. Deswegen trat Karl in einem Schreiben vom 14. Juli ${ }^{2}$ ) mit der Konzilsforderang an den Papst heran. Bei dem Widerstand der lntherischen Fürsten und bei der lauen Haltung der katholischen erweise es sich als unmöglich, im Wege richterlichen Verfahrens die Glaubensspaltung za beseitigen. Er and die trea gesinnten

\section{S. XXXVIf.}

1) Concilinm Tridentinum IV 1. Freibarg i. B. 1904 (ed. Ehses)

2) Heine a. a. O. S. 522-525. 
Karftursten seien der Überzengang, daß man den Wunsch der Protestanten erfullen and ein Konzil berufen musse. Naturlich mubten die Häretiker versprechen, bis dahin die Nenerangen aufzugeben; schon das werde ein großer Erfolg der Berufung des Konzils sein.

Mit welchen Hintergedanken die allzu kluge Politik des Kaisers gefuhrt wurde, verriet Granvella dem päpstlichen Legaten: hätten die Latheraner jene Bedingung einmal angenommen and die Nenerungen in Erwartang des Konzils eingestellt, dann musse man es machen wie Solon, der die Athener vor seiner Abreise habe schwören lassen, dab sie seine Gesetze bis za seiner Wiederkebr halten wurden, and dann niemals mehr nach Athen zuruckkehrte ${ }^{1}$ ).

Aus dieser Bemerkung sehlob Campegio, wohl mit Unrecht, daß es dem Kaiser gar nicht so sehr um die Berufang des Konzils zn ton sei; aber er sah die Lage der Dinge insofern klarer, als er es fur nnmöglich hielt, dab die Protestanten ein Konzil mit dieser Auflage annehmen wtirden. Ftr die Leiter der kaiserlichen Politik war sie anch in erster Linie ein Mittel, dem Papst das Konzil mondgerecht za machen. Wie wir bald hören werden, wünschte der Kaiser die Einberufung des Konzils um jeden Preis, ganz unabhängig davon, ob sich die Protestanten jener Bedingang anterwurfen oder nicht. $\mathrm{Da} \beta$ es unentbehrlich sei, läbt er immer wieder nach Rom melden: "Ich wunschte, es ginge ohne das. Aber es gibt sicherlich keinen anderen Weg')."

Zugleich setzte Karl auch am Reichstag seine Vermittlungspolitik fort. Die Entwurfe der „Konfutation“ der Angustana hat er wiederholt in versöhnlichem Sinn umgestalten lassen ${ }^{8}$ ). Der Versuch Campegios, eine schärfere Kundgebung des kaiserlichen Willens in den Text za bringen, mißlang. Nor der Schlaß der am 3. Angast verlesenen

1) Campegio an Salviati 14. Jnli und 29. Juli Ehses, Römische Quartalschrift XVIII 363 and 369.

2) Karl V. an Loaysa. 2. Augast. Beilage Nr. 3.

3) Johannes Ficker, Die Konfutation des Augsbargischen Bekenntnisses. Ihre erste Gestalt und ihre Geschichte. Leipzig 1891. S. LII and LXXV. 
Schrift enthielt Sätze, die als eine Drohung mit der Exekution von Reichs wegen aufgefabt warden.

In einem Gespräch rom 9. Angust ${ }^{1}$ ) sucbte Campegio anfs neue, den Kaiser zu gewaltsamem Vorgehen zu bestimmen, stieb aber dabei wieder anf die entschiedene $A b$ neigung Karls: ein Turkenkrieg, die Verbindung der Schweizer mit den Protestanten, selbst eine Revolution des niederen Volkes seien zu befurchten. Bei dieser Audienz hat Campegio dem Kaiser auch den Brief Klemens' VII. vom 31. Juli ${ }^{2}$ ) uberreicht, die Antwort anf das Sehreiben Karls vom 14. Juli. Ausfubrlich werden die Bedenken gegen das Konzil vorgetragen. Im Vertranen auf die genauere Kenntnis des Kaisers, der die Lage in Deutschland besser uberschane, willigt aber der Papst in die Berufung des Konzils, jedoch nar anter der ron Karl selbst gestellten Bedingung. Wenn dartber Einigung erzielt sei, werde der Papst die Ladungen ansgeben lassen. Hinsichtlich der abzustellenden MiBbränche in der Kirche verspricht er, die erforderlichen MaBregeln zu ergreifen, sobald er des näheren informiert sei. Nach Verlesung des Briefs sagte Karl za Campegio, dab er darans ersehe, wie ungern der Papst anf den Konzilsplan eingehe. Was die von den Protestanten zu erftllende Bedingang angehe, so sei das Konzil gar nicht allein am der Häretiker willen za berafen, sondern zam Heile der ganzen Christenheit!

Drei Monate ließ der Kaiser verstreichen, ehe er jenen Brief des Papstes vóm 31. Jali persőnlich erwiderte und den Kouzilsplan weiter förderte. Eine Antwort ist erst am 30. Oktober ansgefertigt and von einem besonderen Botschafter, Pedro de la Cacoa, nach Kom gebracht worden ${ }^{8}$ ).

1) Campegio an Salviati 11. August. Lä m mer, Monumenta Vaticana (Freiburg i. B. 1861) S. 49 ff. Über das Datum vgl. Ehses, Römische Quartalschrift XIX 129.

2) Concilium Tridentinum IV. 1 (ed. Ehses) S. XLI-XLIII.

3) Pastor, Geschichte der Päpste IV, 2 S. 418, spricht auf Grand falscher Interpretation eines Briefes des Francesco Gonzaga davon, daß der Kaiser am 4. Oktober an den Papst ein Schreiben gerichtet; habe. Aus seinem Brief vom 30. Oktober ergibt sich aber mit Sicherheit, daß es der erste ist seit Enpfang des Breve rom 31. Juli. Am 
In der Zwischenzeit hat Karl dem Papst mehrmals durch seine Gesandten versichern lassen, da $\beta$ die Beautwortung bevorstebe, immer aber mit dem Zusat $\iota$, daB er warten wolle, bis er uber den Ausgang der Verhandlungen in Angsburg klarer sebe ${ }^{1}$ ).

Indessen ist schon im August im Kabinett des Kaisers eine Antwort auf das päpstliche Schreiben eingebend erwogen worden, wie wir mehreren Vorarbeiten und Entwurfen entnehmen können ${ }^{2}$ ). In einem Gutachten zu dieser Frage ${ }^{8}$ ) wird ansgesprochen, daß der Brief rom 31. Juli zwischen den Zeilen die tiefe Abneigung des Papstes and der Kardinäle gegen ein Konzil, das in seinem Reformeifer sich zuerst gegen die Spitzen der Kirche richten könne, erkennen lasse; man solle aber in der Antwort von diesem Eindrack sich nichts merken lassen, sondern nur versichern, dab der Kaiser keine Minderung der Person und der Macht des Papstes darch das Konzil dulden werde.

Hiervon ist in dem letzten der damals angefertigten Entwurfe ${ }^{4}$ nicht die Rede. Eindringlich sucht das Schreiben za erweisen, daß die Lage in Dentschland die anverzugliche Berufang des Konzils nötig mache. Der Kaiser habe die Antwort so lange hinausgeschoben, am erst zu sehen, ob er nicht auf anderem Wege zum Ziele komme; das würde ihm um so lieber gewesen sein, als er möglichst rasch nach Spanien zartickzakehren wunsche und deswegen gerue das Konzil verschieben wirde. Es bestehe Hoffnung, daB man mit den abtrunnigen Fursten za einer Einigung gelangen werde, and

4. Oktober hat der Kaiser an einen seiner Gesandten in Rom, an Muxetula, schreiben lasseu, und hierauf spielt Francesco Gonzaga an. (S. unten S. 56.)

1) Z. B. in den Briefen an Miguel Mai rom 23. September (s. unten S. 55 Anm. 1) and an Loaysa vom 20. Oktober (8. Beilage Nr. 6).

2) Beilage Nr. 4. Für die Datierung des unter IV. wiedergegebeneu Schreibens ergibt sich als frühester Termin etwa der 20. August, da sich der Kaiser zo Anfang entschnldigt, daß er das ihm am 9. August eingehändigte Schreiben erst jetzt besntworte, als spätester der 28. Angust, da der Optimismus des Schreibens über den Fortgang der Verhandlangen nach den Ereignissen des 29. unverständlich wäre.

3) Beilage Nr. 4 I.

๑) Beilage Nr. 4 IV. Der erste Entworf ist inhaltlich wenig verschieden von dem $\mathrm{z}$ weiten. 
dann könne man mit den Städten rasch fertig werden ${ }^{1}$ ). Aber die trengesinnten Fürsten versicherten, dab sie die Aufgabe der dogmatischen Irrtumer vos den Protestanten nur durch das Versprechen erlangt hätten, daß das Konzil bald berufen werde. Das Bedenken der Kardinäle, daB längst verurteilte Häresien nicht nochmals zar Diskassion gestellt werden durften, wäre nur dann am Platz, wenn der Kaiser ,gegen die Schuldigen strafrechtlich vorgehen und wie in anderen Teilen seiner Reiche eine Exekution vornehmen kőnnte". „Da wir es aber mit einer der größten Nationen der Christenheit zn ton haben, ist es das zweifellos geringere Übel, sie dazn zu bekehren, daß sie ihre Irrtumer mit Hilfe der universalen Kirche zam Sohweigen bringen, als sich nicht zu vertragen and sie nicht darin storren za können; da6 sie so gefährlichen Meinungen zam Schaden so vieler Seelen anhängen." Vor allem werde nor durch das Konzil der Wahn ansgerottet werdeu, der den lntherischen Predigern so grobe Aatorität beim Volke gebe: daß sie die ursprungliche, erst von Rom verderbte Kirche wiederherstellten. Das gemeine Volk könne nicht wissen, was anf frtheren Kouzilien beschlossen worden sei, aber die Entscheidungen eines neuen Konzils wurden jenen Verfuhrern den Boden entziehen. Auch der drobende Turkenkrieg sei kein stichhaltiger Einwand gegen das Konzil; denn es werde gerade der richtige Ort sein, um tiber die Verteidigang der Christenheit zn beraten. Die Bedingang, daß die Protestanten bis zam Konzil zar alten Kirche zartlckkehrten, wird nicht ansdrucklich anerkannt; es wird nur gesagt, der Kaiser werde sich alle Muhe geben, daB die Protestanten bis dahin „alles, was mit ihnen ansgemacht wird, mit demjenigen Gehorsam beobachten, den sie der katholischen Kirche schulden and fruher geleistet haben". Schließlich äußert sich der Kaiser noch sehr erfreut uber die Bereitwilligkeit des Papstes, kirchliche Mißbräuche abzustellen.

Der Brief ist offenbar geschrieben anter dem Eindruck des gunstigen Fortgangs der Verhandlangen in dem Vier-

1) Die gleiche geringschätzige Beurteilung der Städte findet sich z. B. in dem Briefe Campegios an Salviati vom 20. Angast (Lämmer S. 55). 
zehneransschaB, der seit dem 16. Angust einen nenen Vermittlungsversuch unternahm. Die Konzessionen der Protestanten - Melanchthon wollte sich ja sogar zar Wiederherstellung der bischöflicben Gewalt verstehen -, das Entgegenkommen, das die katholische Majorität in einzelnen Fragen, wie z. B. der des Laienkelchs, bewies, rückten eine Verständigang in deu Bereich der Möglichkeit, so daB die Hoffnungsfreudigkeit des kaiserlichen Kabinetts verständlich ist. Aber sie erwies sich bald als trugerisch. Am 29. Angast erklärten die Latheraner, dab sie weitere Konzessionen zu machen nicht in der Lage seien, and alsbald reichte auch der Kurfurst von Sachsen sein Abschiedsgesuch ein. Es wurde klar, daB man nicht einig werden konnte. Jener Brief an den Papst, der ron günstigeren Voraussetzungen ansgegangen war, wurde deshalb nicht ansgefertigt.

Statt dessen wurde am 4. September an Mai geschrieben ${ }^{1}$ ), daB die Verhandlangen vor dem Brache ständen; der Kaiser wolle es nochmals mit persönlichem Eingreifen versuchen; je nach dem Erfolg musse man die weiteren Entschltusse fassen, wenn anch „fur gewaltsames Vorgehen, das am meisten ntttzen würde, die nötige Zartstang fehlt". Jene Unterhandlong in Karls Gegenwart fand am 7. September statt ${ }^{2}$ ) Er lie $B$ den Latheranern nochmals das Konzil versprechen anter der Bedingang, dab sie sich bis dahin "mit ihrer kaiserlichen Majestät und gemeinen Ständen" hielten. Wenn sie sich auf keine weiteren Verhandlungen einlassen wollten, werde er sich als ein "Vogt and Schutzherr der Kirche" erzeigen.

So batte sich die Lage Anfang September zugespitzt: Kaiser and Stände, gleichviel ob alt- oder neuglänbig, forderten die Berufung eines Konzils. Aber mit ganz verschiedenen Absichten. Die Katholiken hofften auf einer allgemeinen Versammlnng der Christenheit der Häretiker leicht Herr zu werden. Die Protestanten hatten von jeher ein "christliches,

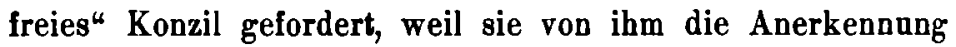

1) Gedruckt bei Sandoval, Historia de la vida $y$ bechos del emperador Carlos V. Barcelona 1625, S. 103.

2) Förstemann, Urkundenbuch za der Geschichte des Reichstages zu Angsburg im Jahre 1530. 2. Bd. (Halle 1535) S. 391-397. 
ibrer Lehren erwarteten. Die Bedingung, daß sie bis zam Kouzil alle Nenerungen ruckgängig zn machen hätten, konnten sie deshalb unmöglich annehmen; sie hätten ibren Besitzstand aufgeben müssen. In den Verhandlungen mit der Karie hatte der Kaiser angedeutet, daß die Berufang des Konzils erfolgen musse, auch wenn jene Voraussetzang nicht vollkommen erfullt sei; in diesem Sinne waren anch im August den Protestanten bestimmte Zngeständnisse fur die Zeit bis zum Konzil gemacht worden. Da die Latheraner nicht weiter nachgeben wollten and der Kaiser jene Forderang in aller Sehroffheit wiederholte, war es dentlich, dab die Gegensätze nicht za therbrucken waren. Za einem „Anstande“, wie er später geschlossen warde, wollte sich der Kaiser noch nicht bequemen. Wollte er seinen Willen darchsetzen dann mubte er za anderen Mitteln greifen.

Im Laufe des September hat die kaiserliche Diplomatie verschiedene Versuche unternommen, um die fehlende „Zarustung" fur einen Waffengang mit den Protestanten zu beschaffen. Diese Vorbereitangen entsprangen nicht etwa einem entschlossenen Kriegswillen des Kaisers. Er suchte nur sondierend festzustellen, was möglich sei, welche Kräfte ihm fur einen gewaltsamen Austrag des Konflikts zar Verfugang stunden. Denn er war sich bewabt, daB er allein der Aufgabe nicht gewachsen war.

Vor allem wollte er sich der Hilfe der dem alten Glanben anhängenden Reichsfursten vergewissern. Etwa am 8. September hat der Kaiser in französischer Sprache ein Memorial ${ }^{1}$ ) verfaBt, das er den katholischen Reichsfursten zngehen lieB. Angesichts der Bartnäckigkeit der Protestanten musse er sich anf die Pflichten seines kaiserlichen Bernfs besinnen. Als Schutzherr der Kirche habe er die alte Lehre und Tradition za schirmen. Wenn die Protestanten ihn uberzeugt hätten, daB ihre Lehre in der Schrift fundiert sei, würde er nicht mit ihnen streiten. „Kaiserliche Majestät ist nicht weniger anf ihr Seelenheil bedacht als andere, um so mehr, je größer die ihr von Gott verordnete Gewalt and

1) Rainaldi Annales ad. 1530 Nr. 100-103. 
Autorität ist." $\mathrm{Da}$ Freundlichkeit nicht verschluge, wolle er weder Leben noch Kräfte schonen, am mit der Hilfe Gottes und dem Rate der Kurfursten zn tan, was notwendig sei. Er werde aach den Papst and die anderen christlichen Fursten am ihre Hilfe bitten. Wenn die Protestanten bis zam Konzil zar Kirche zartickkehrten, wurden ibre Nenerangen im Geiste christlicher Barmherzigkeit gepruft werden. Wo nicht. könnten der Karfurst von Sachsen and seine Anhänger von der Milde des Kaisers nichts mehr erwarten; sie mubten dann gezwangen werden, dab sie sich dem Konzil stellten und ihre Sache verträten. Unbedingt seien die geistlichen Guter zuruckzuerstatten und dem Kaiser zur Verwaltang zn ubergeben. Die Fursten werden schließlich aufgefordert, ihr Gatachten in den beruhrten Fragen abzugeben.

Sieht man anf den Kern der kaiserlichen Denkschrift, so erkennt man hinter ihrer vorsichtigen Form den Wunseh Karls, die katholischen Fursten ftr ein Kriegsbundnis zu gewinnen. Charakteristisch ist nun, wie sich die Stände zu diesem Angebot verhalten. Um die Verhandlangen zwischen ihnen und dem Kaiser zu vereinfachen, wurde ein Achteranssehuß damit beanftragt. Aus seinen ersten Änßerungen ${ }^{1}$ ) war zu entnehmen, daß die Fursten mit der Möglichkeit einer Vermittlung immer noch rechneten und auch erwogen, ob man nicht manchen der latherischen Irrtimer dulden könne. Für den Fall, daß mit Strenge vorzagehen wäre, bevorzugten sie ein gerichtliches Verfahren.

Anf diesen Ausweg verfielen also die katholischen Stände: darch kammergerichtliche Prozesse wollten sie von den Protestanten die Herausgabe der geistlichen Guter erzwingen. In den eigentlich dogmatischen Fragen waren sie nachgiebig. Einen Krieg wüschten sie za vermeiden, da er eine unbequeme Steigerung der Kaisermacht bringen konnte.

1) Gedruckt bei E h s e s, Römische Quartalschrift XX 54 unter dem Titel ${ }_{n}$ A ntwort der katholischen Fürsten suf die Denkschrift Karls V. ${ }^{*}$. Das Aktenstiuck ist njcht eigentlich eine Antwort, sondern eine Aufzeichnnng einzelner Fragen, die bei den mündlichen Besprechungen za behandeln sind. 
Mit ibrer ersten Antwort gab sich der Kaiser nicht zafrieden. Er wiederholte ihnen nochmals die Erklärnng, daB er um des Glaabens and der kaiserlichen Autorität willen und ans besonderer Liebe zar dentschen Nation sein Leben and sein Gat furr die Regelung der Glaubenstrage einsetzen wolle. Er bat um nähere Ausfubrang ibrer Ratschläge ${ }^{1}$ ).

Darauf gaben die katholischen Stände am 16. September eine eingehendere Erwiderang ${ }^{2}$ ), in der ihre Abneigung gegen den Krieg deutlicher zam Ausdrack kommt. Sie stellen sich, als ob sie den wabren Sinn der kaiserlichen Denkschrift nicht verstunden and berafen sich auf Karls eigenen Wunsch, daB der Krieg vermieden wurde. Sie gehen soweit, dem Kaiser dafur za danken, daß er „die Zerstörung der deatschen Nation", wie sie ein Krieg mit sich bringeu wurde, verhindern wolle. Ans ihrem Ratschlag werde der Kaiser schon entnommen haben, daß sie in keiner Weise einem gewaltsamen Vorgehen das Wort geredet hätten. Man solle dem Legaten begreiflich machen, da 3 man soweit wie möglich gehen musse, am eine Einigang za erzielen. Über die Form der Kriegfuhrung brauchte ja nicht gesprochen zo werden, da der Kaiser zum Frieden entschlossen sei; sollte er sich anders besinnen und sich unbedingt fur den Krieg entscheiden, wtirden die Stände ihr Gutachten nicht verweigern. Sie seien auch bereit, mit dem Kaiser Abmachungen uber eine gemeinsame Verteidigung im Fall eines Angriffs von seiten der Latherischen einzagehen. Unamgänglich sei die baldige Ansage des Konzils.

Ans dieser diplomatisch sehr geschickten Erwiderang der katholischen Stände ist zo entnebmen, daB die mulndlichen Anträge des Kaisers noch weiter gegangen sein mulssen als die schriftlichen; wunschte er doch ihren Rat uber die Vorbereitung und die Anlage des Feldzags!

Aber das Ergebnis dieser Rekognoszierang im katholischen Lager war fur den Kaiser nicht sehr ermutigend. Campegio hatte ihm vorgestellt, dab die altgläubigen Fursten ihm folgen würden, wenn er ihnen nar den Weg wiese ${ }^{3}$ ).

1) A. a. $0.8 X 55 \mathrm{ff}$.

8) A. a. 0. $X X 57$.

3) Campegio an Salviati 13. September. E h s e 8 8. 8. O. XLX 146. 
Das war unrichtig: wohl lieb anch die kaiserliche Politik einen entschlossenen Willen vermissen mit Rucksicht anf die mangelhafte Rüstang and die auswärtige Lage, aber entscheidend war die Abneigang der Fursten gegen einen Krieg.

Deshalb war es klar, dab die Kriegspläne znm mindestev verschoben werden mußten. In jenem Achterausschn $B$ warde ein Entwurf des Reichstagsabschieds aufgesetzt, der den Protestanten bis zum 15. April Bedenkzeit gab ${ }^{1}$ ). Die Lutheraner weigerten sicb, ihs anzanehmen, und daruber kam es in Gegenwart des Kaisers am 23. September za heftigen Auseinandersetzungen zwischen ihnen und Joachim von Brandenburg, der sie einzuschuchtern sucbte mit der Erklärung, der Kaiser sei mit den katholischen Ständen einen Bund eingegangen and werde anch die ubrigen christlichen Fursten um Hilfe ersuchen, damit der neae Irrtum und die neae Sekte ,gänzlich ausgerottet und dentsehe Nation wiederam za christlicher Einigkeit gebracht" werde ${ }^{2}$ ). Joachim sprach ans, was der Kaiser wünschte. Wie wenig Anklang er aber bei seinen eigenen Glanbensgenossen damit fand, das beweisen die Entschuldigungen, die die Räte des pfälzischen Karfursten seiner Drohungen wegen bei den Kursachsen vorbrachten, und ähnliche Erk]ärungen Albrechts von Mainz und des Herzogs Ludwig von Bayern.

Kriegerischer war die Sprache des Kaisers in dieser Zeit. Es war nicht nur der Zorn des Augenblicks, der ihn an jenem 23. September ausrufen ließ, nun seien nicht mehr Worte and Unterhandlangen, sondern nar die starke Hand am Platze ${ }^{8}$ ). Damals empfing anch Campegio die Genugtuung, daß Karl ihm zagab, was er ihm bisher verweigert hatte: falls die Latheraner bis zan 15. April keine Einigung herbeifuhrten, sei er entschlossen, sie zu zuchtigen; aber dazu brauche er die Hilfe anderer ${ }^{4}$ ).

1) Förstemann a. a. O. II $\mathbf{4 7 4 f f}$.

2) Walch, Lutheri sämtliche Schriften (Halle $1749 \mathrm{ff}$.) XVI $186 a \mathrm{ff}$.

s) Ebses a. a. O. XX 63.

) Campegio an Salviati 24. September. Lämmer, Monumenta Vaticana S. $57 \mathrm{f}$. Vermatlich in diesen Tagen sind in des Kaisers Umgebung entatanden die Articnli aliqui notati quomodo et qualiter Caesar rebelles in fide panire possit". Manrenbrecher, Karl V. und die deutschen Protestanten. S. 16*-21*. 
Nachdem der Kaiser zuerst bei den katholischen fursten am Beistand geworben hatte, wandte er sich nun an $d$ e $n$ Papst mit einer Bitte am Sabsidien. Er unternahm einen weiteren Versuch, Mittel bereitzastellen, die ibm gegebenenfalls ermöglichen soliten, den Konflikt durch das Schwert zam Austrag za bringen. Die Form, in der das geschab, zeigt anschaulich, wie die dentsche Glaubeusspaltung eben doch nur e in e der verschiedenartigen Schwierigkeiten war, die Karl zu lösen hatte; gerade die Fulle seiner Aufgaben lieb keine recht zar Erledigung gelangen.

Karl war ohne Truppen uber die Alpen gezogen. Die spanische Infanterie, die er nach Italien mitgebracht hatte, war dort fur die Belagerung von Florenz verwandt worden. Nach dem Falle der Stadt stand dies Kontingent rou 5 bis 6000 Spaniern zar freien Verfugang, ebenso italienische Truppen. Freilich schien es angesichts der unsicheren Lage in Italien und der Revanchegeltuste Frankreichs nicht ungefährlich, Italien von Truppen za entblößen, und die Vertreter des Kaisers warnten dringend davor. Jedenfalls wollte man dieses kleine stehende Heer, das einzige militärische Machtmittel, das Karl fur Mittel- und Norditalien, fur Ungarn und fur Dentschland zar Verfugang stand, erhalten, und da die kaiserlichen Kassen wie immer erschöpft waren, suchte man die Mittel anf anderem Wege aufzubringen.

Am 23. September lieb der Kaiser an Migael Mai and an Loaysa schreiben, dab er die Hoffnung an eine Einigang in der religiösen Frage aufgegeben habe ${ }^{1}$ ). Gleichzeitig bekam Juan Antonio Muxetula, der schon mehrfach von Karl in besonderen Missionen verwandt worden war and sich

1) Der Kaiser an Miguel Mai, Auggburg, 23. September 1530 (Simancas, Estado 1557 fol. 99-101. Ein Rogest dieses Briefes gibt Gay angos, Calendar of State Papers [Spanish] vol. IV part I n. 434); ... Lo de la fee esta, como os screvimos, en muy malos termines, que todo lo que si ha trabajado y trabaja, que no ha sido poco, no ha aprovechado para reduzirlos a ningand buen medio, de que no estoy con pequeño cuydedo. Agora se traban algunos, para que sobresean en seguir sus errores y opiniones hasta el concilio. No respondemos a su Sat sobre ello, hasta que se tome resolución ... Vom gleichen Tage datiert ist ein ähnlich gehaltener Brief an Garcia de Loaysa (Simancas, Estado 1558 fol. 59). 
gerade damals als kaiserlicher Kommissar im Heere vor Florenz befand ${ }^{1}$ ), den Befehl, nach Rom zu gehen and mit der Karie uber die Verwendang der 5-6000 Spanier zu verbandeln ${ }^{2}$ ). Sie za entlassen, verbiete die Lage in der Christenheit. Um den Glauben stände es angenblicklich so schlimm in Dentschland, daß Papst and Kaiser auf der Hot sein muBten; „da der Winter herannabt und die nötige $\mathrm{Zn}$ rllstang fur GewaltmaBregeln fehlt, maß die Exekution etwas verschoben werden“. Andererseits drohe fur das Frühjahr ein neuer Turkenkrieg, und in Italien konnten anch Verwicklungen eintreten. Aus diesen drei Grttnden mubten jene 5-6000 Spanier und ein Teil der italienischen Trappen in Sold behalten werden. Ihr Zweck werde am besten erfullt, wenn man sie nach Ungarn rerlege, von wo sie leicht nach Deatschland gebracht werden könnten, am als Kern eines gröberen, durch deutsche Landsknechte verstärkten Heeres za dienen, und ${ }_{n}$ wenn es nötig ist, Gewalt zu gebrauchen in der Glanbenssache“. "Wenn sie in Ungarn stehen, werden die Protestanten vielleicht schon dadurch veranlabt, za ihrer Pflicht zurtickzukehren, von der sie jetzt weit abgewichen sind; deswegen muB ibnen ein Aufschub gewährt werden, bis man za besserer Zeit sieht, was sich machen läbt." $\mathrm{Da}$ dies Heer in Ungarn jederzeit anch zam Schutz Italiens und zar Verteidigang von Florenz verwandt werden kann, muß von den italienischen Staaten ein Beitrag za den Kosten erwirkt werden. Der Papst möge in diesem Sinne eine Aufforderung an die italienischen Fursten ergehen lassen und selber seinen Anteil an der Kontribation zablen.

Am 4. Oktober ging ein zweites kaiserliches Schreiben an Muxetala ${ }^{8}$ ) ab, das am 16. in der Kongregation der mit den deutschen Angelegenheiten betranten Kardinäle verlesen warde: Waffengewalt erscheine dem Kaiser and einigen

1) Gayangos, Calendar of State Papera (Spanish) IV, 1 pag. XI.

2) Karl V. an J. A. Muxetula 23. September 1530, s. Beilage Nr. o. Vom gleichen Tage ist das Kredenzschreiben für Muxetula datiert (Simancas, Estado 1557 fol. 98).

2) Das Schreiben liegt mir nicht vor. Über seinen Inhalt berichtet Loaysa im Brief an den Kaiser vom 20. Oktober 1530 (Coleccion de documentos ineditos XIV, 92). 
katholischen Fursten als das einzige Heilmittel (la fuerza era el remedio). Der Papst musse aber Hilfe leisten and die christlichen Fursten daza bewegen, das gleiche za tun. Sämtliche Kardinäle, mit Ausnahme des französischen, sprachen sich fur Erfullung dieser Wunsche aus.

Campegio glanbte seinen Weizen anfbluhen zu seben und warnte die Kurie davor, den Eifer des Kaisers erkalten zu lassen; dazu seien aber von ihrer Seite Taten, nicht nur Worte nötig ${ }^{1}$ ).

Es ist unmogglich za entscheiden, inwieweit bei diesem Hilfegesach Karls der ernsthafte Wille, den Ketzerkrieg vorzubereiten, mitsprach, and inwieweit der Kriegsplan nar ein Vorwand war, am das Geld fur den weiteren Unterhalt der spanischen Truppen aufzatreiben. Jedenfalls erweist dieser eigentumliche Vorgang wieder, anf wie schwachen militärischen Grundlagen Karls Weltmacht ruhte.

Bei der Agitation futr die Sabsidienzahlung der italienischen Staaten wurde von der Kurie vorwiegend mit der Begrundung gearbeitet, die Truppen sollten fur den Ketzerkrieg dienen; die beiden anderen Grttnde, die das kaiserliche Schreiben in gleicher Linie vorgebracht hatte, der Turkenkrieg and die Erhaltung des Friedens in Italien, traten zarick ${ }^{2}$ ). In dieser Form kam die Nachricht auch nach Venedig, and zufolge der Schilderung des kaiserlichen Gesandten erregte es dort heiteres Erstannen, daß der Papst glanbe, die Stadt werde ihm eine Beihilfe fur den Kampf gegen die Protestanten gewähren. Er mlsse sehr schlecht informiert sein uber die Stimmang in Venedig. Es gebe dort eine starke lntherische Partei, and die ganze Stadt wtunsche das Konzil, damit dem Papst Ungelegenheiten erwuchsen. Wie sollte da Venedig einen Finger rthren, um ihm das Konzil zu ersparen ${ }^{8}$ )?

Miguel Mai scheint fur diese Kriegslust in Rom anßer

1) Campegio an Salviati 4. Oktober. Ehses, Römische Quartalschrift XX $69 \mathrm{f}$.

2) Francesco Gonzaga an Federigo Gonzaga 19. Oktober. Gedruckt bei Pastor, Geschichte der Päpste IV, 2, S. 758.

? Rodrigo Niño an Miguel Mai, Venedig 27. Oktober, s. Beilage Nir. 8. 
dem Wunsch der Kurialen, durch den Waffengang das Konzil za vermeiden, das Gebaren Maxetalas verantwortlich gemacht za haben. Wenigstens hat er diesen in Gegenwart von Zengen gebeten, nicht uber die Linie der kaiserlichen Instruktionen hinanszugehen, and ibn darauf anfmerksam gemacht, dab in den Briefen des Kaisers von einem Kriegsentschla $B$ nicht die Rede sei, sondern nar davon, daB er $n$ das Heer weiter erhalten and Kräfte sammeln wolle, um sich ihrer zu gelegener Zeit, wenn es nötig sei, zu bedienen" "1).

Allgemein herrschte die Überzeugung, daB der Papst die Kriegspläne des Kaisers mit großer Freude aufnehmen werde, da sie ihn der Sorge des Konzils enthöben. Ohne Frage war bei den Kurialen dies Motiv maßgebend. Vor die Alternative gestellt: Krieg oder Konzil, war für sie die Wahl nicht zweifelhaft. Auch Klemens VII. hat zeitlebens den Konzilsplan als eine persönliche Beleidigung empfunden. Aber er wäre nicht der Mann von krankhafter Unentschlossenheit gewesen, der er war, wenn er nicht auch in diesem Fall, wo doch der gegebene Weg so klar vorgezeichnet schien, in sein gewohntes Zandern rerfallen wäre. Zwar sprechen die offiziellen Schreiben Salviatis an Campegio von der Genugtunng des Papstes, da $B$ der Kaiser endlich der Frechheit der Ketzer energisch entgegentreten wolle; Clemens geht auch anf den Wunseh Karls in betreff der Subsidienzahlung ein und will zu dem Behuf Breven an die italienischen Fursten and Staaten schicken ${ }^{2}$ ). Aber von Eingeweihten hören wir, dab der Papst vor lauter Sorgen tuber die Ausfuhrung des Planes za keinem Entsehlub komme. Wobl sei es fur die Autorität des Kaisers and des Papstes eine gefährliche Einbaße, wenn die Ketzer nicht bestraft wurden; aber der Krieg koste viel Geld, and es bestehe die Gefabr, daB die Lutheraner sich mit den Fursteu verbänden ${ }^{8}$ ). In seiner Bedenklichkeit ging Klemens so weit, dab er in jenen Breven von der Absicht, die Truppen fur den Ketzer-

1) Migael Mai an Coros 21. Oktober, s. Beilage Nr. 7.

2) Salviati an Campegio 13. a. 21. Oktober. Ehses, Römiscbe Quartalschrift XX 76 u. XXI 114.

3) Francesco Gonzaga an Federigo Gonzaga 19. Oktober a. a 0. 
krieg za verwenden, vichts verlanten lassen wollte. Da die Kopie dieser Breven von Hand za Hand gehe, sei Gefabr vorhanden, daB sie den Protestanten in die Hände fielen and sie reizten ${ }^{1}$ )! Umgekebrt bat der Kaiser, den Ketzerkrieg in den Vordergrand za stellen, nicht den Türkenkrieg; denn mancher - dabei mag er wohl an Venedig gedacht haben - leiste vielleicht ungern der Machtentfaltung König Ferdinands Vorschab ${ }^{2}$ ). So scheinen die Rollen zwischen dem geistlicheu and dem weltlichen Haupt der Christenheit rertauscht!

Das Subsidiengesuch in Italien fand nur bei Wenigen Gehör, und der Ertrag war ganz gering. Weil man das Land nicht angedeckt lassen wollte, unterblieb zanächst anch die Entsendong der spanischen Trappen nach Ungarn and kam erst im Sommer 1532 zur Ausfubrang. Die Erhaltung der spanischen Suprematie in Italien war letzthin fur den Spanier Karl wichtiger als die Restauration der Glanbenseinheit and der Kaisermacht in Dentschland.

Ebenso geringen Erfolg zeitigten die Bundnisverhandlungen in Deutschland. Mitte Oktober wurde noch einmal der Versuch gemacht, die katholischen Stände in einem Defensivbunde zu einigen und gegen etwaige Angriffe durch die Protestanten zu sichern \%). Karl maBte sich aber mit einer allgemeinen Formel im Reichsabschied begnugen: alle, die ihn annahmen verpflichteten sich und sagten sich $z 0$, dab "keiner von geistlichem oder weltlichem Stand den anderen des Glanbens halber vergewaltigen, dringen oder uberziehen durfe ${ }^{(4)}$ ). Anfang 1531, anlä日lich des zum Schatz der Wahl Ferdinands abgeschlossenen Bundes, trat man abermals mit dem Plan einer Offensivallianz an die katholischen Karfursten herau, wiedernm vergeblich ${ }^{5}$ ).

1) Miguel Mai an den Kaiser 28. Oktober. Beilage Nr. 9.

2) Campegio an Salviati 11. November. Lämmer, Monumenta Vaticana S. 63.

9) Förstemann, Urkundenbuch II 737.

4) Neae und vollständige Sammlang der Reichsabschiede. Frankfurt 1747. T. 2, 316-317. $\$ 66,72$.

b) Lang, Staatspapiere zur Geschichte Karls V. Stuttgart 1845. S. 57; Ranke S. W. 6, $141 \mathrm{ff}$. 
Wie die Verständigang, waren also anch die Versuche, eine kriegerische Lösung vorzabereiten, mißlangen. Dartaber brachten die Verhandlangen im September and Oktober völlige Klarbeit. Sie bestätigten Karls MiBtranen gegen seine Kraft. , Ich sebe wobl, daB, wenn es Mittel gäbe, die Ketzer zu zwingen, man sie gerechterweise gegen sie wenden mubte; aber im Angenblick stehen sie mir nicht zur Verfugung, and die Jahreszeit ist sehr ungunstig. Das einzige Heilmittel, das blcibt, ist die Berafang des Konzils. (El remedio que queda es convocar el concilio.)")" So lebte der Konzilsplan ron nenem anf - als ein Ausweg aus der Verlegenheit, nicht wie im Sommer als Preis and Krönung friedlicher Einigung. Wenn die katholischen Stände das Konzil wunschten, am den Krieg zu vermeiden, die Kurialen den Krieg, um das Konzil zu rermeiden, forderte jetzt der Kaiser das Konzil als das einzige Auskunftsmittel, da er den Krieg zwar fur wirksamer, aber im Augenblick nicht fur möglich hielt. Insofern bestand anch fur Karl die Alternative: Krieg oder Konzil. Wenn er aber für das eine wie für das andere seine Vorbereitungen trifft, so wird damit auch jene Möglichkeit angedentet, die später Erftllung werden sollte: daß man das Konzil zar Keform der Kirche berief and zagleich mit Waffengewalt die Protestanten dem Willen des Kaisers unterwarf ${ }^{2}$ ).

Ende Oktober warde Pedro de la Cneva von Karl nach Rom gesandt, und es gehörte zu seinem Auftrag, daß er dort von dem Aufschub des Krieges Mitteilung machte. Der Hauptzweck seiner Mission war, den Papst von der Notwendigkeit des Konzils za uberzengen, and er erreichte auch, dab Klemens wenigstens scheinbar die Unterhandlangen mit den ubrigen christlichen Fursten begann ${ }^{8}$ ).

Es leidet nach den vorliegenden Änßerangen keinen

1) Karl V. an Garcia de Loajsa 20. Oktober 1530, s. Beilage Nr. 6.

2) M surenbrecher, Studien und Skizzen zur Reformationszeit Leipzig 1874. S. 127: „Der Krieg gegen die Protestanten war die Ergänzung der konziliaren Leistungen.“

s) Die Instraktion für Pedro de la Cueva rom 30. Oktober bei Heine a. a. 0., S. 525-529. Ebenda der Brief des Kaisers an den Papst (S. 530-533). 
Zweifel, daB der Kaiser, seitdem die Hoffnung auf die Nachgiebigkeit der Protestanten sich als eine Illusion erwiesen hatte, die Sache am liebsten mit dem Schwert ansgetragen hätte. Aber seine Politik empfing ihr Gesetz ron fremden Gewalten, ror allem doch von dem stindischen Geist des Deutschen Reiches. Es erhellt aus den Verhandlangen mit Deutlichkeit, daß die katholischen Fursten die Treibenden bei der Konzilsforderang des Kaisers waren, and daB der Kriegsplan vor allem an ihrem Widerstand scheiterte. Diese Stellangnahme war fur sie ein Gebot der Selbsterhaltung. Wäre die Macht der protestantischen Stände gemindert worden, so hätten anch die katholischen unter den Ruckwirkungen za leiden gehabt.

Wie ängstlich sie uber der Erhaltung der ständischen Rechte auch der häretischen Fursten wachten, das sollte der Kaiser nun anch bei den Verhandlangen uber die Königswahl erfahren.

\section{Beilagen ${ }^{1}$ ).}

Nr. 1.

Miguel Mai an Covos: Gegen die Teilnahme des Kaisers am Keichstag.

Rom 1530 Mai 15.

Simancas Generalarehiv, Estado legajo 853 fol. 36.

... Dizen que se ha de hazer dieta en Alemania, y estos huelgan de toda cosa que sea dilación del consilio. No sé yo, si conviene al emperador hallarse en ella por dos cosas: la una, porque paresce que más imprime el miedo de dezir: irá que no el ser ido, porque en este caso la presencia les pone más temor y estan más unidos para no poderles entrar; $y$ la otra, que haviéndose de

1) Die ypanischen Texte sind, wie schon erwähnt, einer Sammlung von Abschriften entnommen. die Herr Dr. Josef Schweiger für das PreuBische Historische Institut in Rom angefertigt nnd kollationiert hat. Die mir übertragene Bearbeitung erstreckte sich nur anf Herstellung der änßeren Form, abgesehen von wenigen Stellen, an denen sich ans dem Sinn offensichtlich eine Emendation des Textes ergab; in zweifelhaften Fällen warde von Veränderungen abgesehen. Nach Stieves Regeln habe ich $y$ durch $i$ ersetet, wo das letztere heute üblich ist, and Akzente eingefügt; in der Interpungierung bin ich weiter gegangen, als es die spanischen Regeln zulassen, um dem deutschen Leser das Verstăndnis za erleichtern. 
pactejar con los vellacos hareges, seria más honra que se hiziesse por otra mano. A este respecto dixe el otro dia al papa, que si era menester, que su $S^{\text {ad }}$ dispusiesse lo que se havria de condonar á los tales, y respondiome, que le cortassemos hasta la cintura que por ella señalo.

Nr. 2.

Karl V. (Covos) an Garcia de Loaysa: Berichtet uber seine Reise.

Munchen 1530 Juni 14.

Simancas Generalarchir, Estado 1558 f. 74.

Vi vuestra letra del dia de la acensión. A la primera os respondi de Insprach, como avréis visto. Con todas las que me screvis huelgo mucho, y los consejos que me dáis los tomo como de quien sé que tan entrañablemente me ama y desea mi honrra y servicio, y asi recibiré plazer que siempre los continuéis, como lo hazéis. En Inspruch me detuve más dias de los que quisiera; que, como alli venieron $108 \operatorname{Ser}^{\mathrm{mon}}$ rey y reinas mi hermanas y algunos principes, y se començó a platicar en lo que se deve hazer para el remedio de las cosas desta Alemaña, no pude hazer otra cosa. Parti el segundo dia de Pascua y mañana vispera de corpus Christi llegare, plaziendo à N. S'ró á Agusta para andar aquel dia ell la procesión. Alli ine estan esperando los principes electores y otros grandes del imperio, y con toda voluntad de conplazerme y serrirme; espero que se dará tal horden en todo lo de acá, que se reduza á servicio de $\mathrm{N}$. S $\mathrm{S}^{\text {or }} \mathrm{y}$ honrra de la fee catholica $\mathrm{y}$ al bien de la christiandad. Yo estoy may cierto del amor que su $S^{d}$ dezis que me tiene $y$ no dubdo que irá eu crecimiento, por que por mi parte no se faltará á ninguna cosa de las que para esto convengan ... De Munich á 14 de junio 1530 años.

\section{Nr. 3.}

Karl V. an Garcia de Loaysa: Antwort auf den Brief des Adressaten vom 18. Juli. Das Konzil ist unumgänglich.

Angsburg 1530 Angust 2.

Simancas Generalarchiv, Estado 1558 fol. 60.

Vi vuestra letra de 18. de julio y la que screvistes al comendador mayor, mi secretario, $y$, como os tengo seripto, huelgo mucho con todas $y$ de ser de vos aconsejado y avisado, porque tengo conocido el entrañable amor que me tenéis. $Y$ assí os ruego, que no canséis de hazerlo siempre, 
en lo que toca al remedio de las cosas de la fee. Vos lo dezis may bien, y asi es lo que en ello y en todo lo que se ofrece hazéis, porque os doy machas gratias. Por lo que destos se conosce, se tiene por cierto, que ningund medio puede aprovechar, faltando él que allá se ha scripto. La respuesta de su $\mathrm{S}^{\mathrm{d}}$. se espera dello, y yo tengo por cierto, que, como quien tanto le toca y es obligado á procarar el servicio de $\mathrm{N}$. Sor $\mathrm{y}$ la honra y defensión y acrecentamiento de su santa fee catholica, no rehusará de venir en lo que para ello conviene. Yo deseo que se pudiese remediar, sin que esta faese menester. Pero cierto no ay otro ningund medio, y por esto os ruego, que, si ya su $S^{d}$. no estuviere resuelto en ello $y$ fuere menester, ayndéis y encaminéis, como en todo caso se determine luego, pues tanto importa. De mi creed, que con mi persona y con todas mis fuerças me emplearé en esto, sin faltar à ninguna cosa de las que convinieren. Huelgo de saber que estéis con mejor dispusición que otros veranos. Plega a dios que os dé la salud que deseáis. El enbaxador os cumunicará lo que más ay que dezir.

De Agusta á 2 de agosto 1530.

Nr. 4.

Entwutre zn einer Antwort des Kaisers auf das Schreiben des Papstes rom 31. Juli 1530: Konzilsfrage.

Undatiert. Angust 1530?

Simancas Generalarchiv, Libros de Berzosa ${ }^{1}$ ) 8 (2010) fol. $25-29$.

I. Gatachten eines Unbekannten: Die Abneigang des Papstes gegen das Konzil ist offensichtlich. Die Antwort soll seine Besorgnisse zerstrenen.

Las consideraciones que se han de tener para responder á la carta de su $\mathrm{S}^{\mathrm{d}}$, son á mi parescer las siguientes:

Primeramente, que el papa se vee claro que viene de mala gana a la convocación del concilio; antes se deve pensar, que mayor temor ternia su $\mathrm{S}^{\mathrm{d}}$ de la dicha convocación, si pensasse, que el emperador N. S. fuesse él que procarasse la convocación del concilio.

1) Uber diesen Fonds des Archivs von Simancas vgl. Heine, Serapeum VIII (1844) S. 105. Er enthält Kopien, die Juan de Berzosa, den Philipp II. zu seinem Archivar in Rom ernannt hatte, dort anfertigte. Wie die gebeimen Akten und die nie abgesandten Entwürfe des kaiserlichen Kabinetts in diese Sammlung geraten sind, ist unaufgeklärt. 
Item se deve creer, que el mayor miedo del papa y de los cardenales deve ser, que en el dicho concilio se haya de reformar la iglesia universal, començando por la eabeça $y$ los miembros principales, como se deve y suele en todos los concilios passados hazer.

Para remedio de lo susodicho la letra de sa $\mathbf{M}^{d}$ ha de ser fundada en 4 puntos:

El primero, que se acepte $y$ dé gracias por lo que scrive su $S^{d}$ de querer convocar el dicho concilio, sin mostrar de haver entendido la poca gana que dello tiene.

El segundo, scrivir que no quiso dar respuesta á su $\mathrm{S}^{d}$, sin que primero haviesse hecho todas las diligencias possibles para ver, si estos errores de Alemania se pudieran remediar, y que el remedio permanesciera sin la dicha convocación de concilio por quitar à su $\mathrm{S}^{\mathrm{d}}$ de trabajo y á todos los demás.

El tercero, responder y confundir las razones, que en su carta su $\mathrm{S}^{\mathrm{d}}$ trae para colorar, que no sea buena la convocación del concilio, pues ay evidentissimas razones para con verdad poderlas convencer.

El quarto, con efficacissimas palabras offrescer à su $\mathrm{Sd}$, que en esta convocación de concilio $80 \mathrm{M}^{\mathrm{d}}$ no permite $\dot{a}$ que se tracte ni intente cosa que sea on cabello en detrimento de la persona ni estado de su $\mathrm{S}^{d}$, antes terna sobre sus ojos lo que tocare á la honra y exaltación de la sede apostolica, y replicar lo que á boca le prometio en Bolonia sobre esta misma materia etc.

II. Erster Entwarf.

III. Auszug aus dem Schreiben des Papstes rom 31. Juli. Los pantos principales de la carta de sa $\mathrm{S}^{\mathrm{d}}$, à que se ba de responder, son los siguientes etc.

\section{Zweiter Entwurf.}

Recibi la carta de V. $S^{d}$ de altimo de julio y con esta satisfaré á lo necessario della y primeramente le doy muchas gracias por tan buena voluntad, como tiene de querer convocar el concilio, sin tener respecto al trabajo de su persona ni á qualquier otro incomodo, en lo qual hará como verdadero santo padre y muestra bien el amor y cuidado que á las cosas de nuestra santa fee tiene y al remedio y provecho de toda la christiandad; y assí mismo he bolgado que los $\mathrm{R}^{\mathrm{mos}}$ cardenales diputados vengan con tan buen zelo y entera voluntad á este santo proposito.

Assi mismo me han parescido bien todas las prudentes consideraciones que en la dicha carta de V. $S^{d}$ vienen. 
Y acá tambien se me han representado otras razones que á mi persona tocan, como es: considerar la mucha necessidad que havria de mi presencia en los reinos de Españá para muchos buenos effectos, por donde me convernia abreviar la estada de mi persona en estas partes. Y juntados estos respectos con los que $V$. $S^{d}$ serive yo taviera por baeno, que por el presente se dilatasse la convocación del concilio, con que a estos errores y heregias de Alemania se pudiesse dar algan buen remedio; $y$ á este fin no me ha parescido responder á la carta de $\mathrm{V}$. $\mathrm{S}^{d}$, sin tentar primero con los electores y principes del imperio todos los medios possibles para rer, si huviera forma o manera de poner en buen estado estas cosas, porque los principes que estavan may endurescidos en esta falsa opinión por diversos modos se han ya reduzido á se apartar de la mayor parte de sus errores, y acabado de tomar con estos algun assiento se puede esperar, que con las ciudades y pueblos, annque tienen mayores y diversos errores, será más facil el camino de los convencer y retirar al verdadero conoscimiento. Pero ha de saber V. $S^{d}$ que los electores y principes que bien sienten en la fee dizen, que el mayor fundamento $y$ ayada, que han tenido y tienen para traer los dañados á lo susodicho, es: darles certinidad de la prossima convocación del concilio, en el qual por la iglesia universal les prometen que seran declaradas todas las dabdas que agora tienen. $Y$ por tener que hazer no solamente con los hereges que han movido estos errores, mas con todas las más ciudades y pueblos de Alemania, paresce que ay necessidad de anthorizar la opinión verdadera con el dicho concilio, y haviendo consideración à lo susodicho, me paresce: que la dabda que los $\mathrm{R}^{\text {mos }}$ cardenales dipntados hallan en que seria impertinente dar lugar $\dot{a}$ que se tornassen á disputar los errores y heregias que ya estan condemnadas por otros concilios no es bastante, aunque cierto dirfan bien, si se pudiesse castigar el delicto con los derechos y como se executa en otras partes de nuestros reinos. Pero teniendo que hazer con unas de las mayores naciones de la christiandad, se deve tener por menos inconveniente sin ninguna comparación, tornarles á confundir por la nniversal iglesia sus errores que no comportar ó no poderles estorvar, que siguiessen tan dañosa opinión con perdición de tantas animas y de las que más se podrian dañar; que seria may mayor el escandalo y peor exemplo y mucho menos anthoridad de la santa sede apostolica. $Y$ tambien se ha visto en diversos concilios condemnarse una misma heregia por causas y necessidades que sobrevienen.

Arohiv far Relormationsgeschiohte. XIII. 1. 
Y à lo que dizen que no seria medicina bastante, para que aprovechasse más el futaro concilio que los passados, acá les paresce que para los pueblos generalmente no podria sino hazer muy gran provecho viendo la determinación, como dicho es, de la aniversal iglesia; porque los predicadores e inventores destas heregias con la cosa que más han engañado los pueblos, es: darles á creer que en todo lo que agora ellos diffieren de nuestra santa fee no es sino apartarse de las ordenaciones y ritos de la Romana iglesia, llamandolas abnsiones y ranas cerimonias; $\mathrm{y}$ con estas falsas persuasiones en todo $\mathrm{y}$ por todo han procurado de quitar los mandamientos de la iglesia, porque no todo el vulgo puede sāber lo que han condemnado y declarado los concilios passados. $Y$ por esto paresce $\dot{a}$ todos los que tienen el fin bueno y sano en esta negociación, que la declaración del nuevo concilio en esto quitaria de todo panto la authoridad destos predicadores con los pueblos que por ellos han sido seductos y enganados, y con su authoridad se allanaria todo; y siendo el concilio convocado en lugar libre, donde tanta multitud de buenos christianos concurreria, anque algunos toviessen qualquier mala intención, se deve pensar que no se podrian esperar sino buenos effectos.

Quanto al parescer de los dichos cardenales dipntados, que seria inconveniente tiempo el presente para convocar concilio por cansa de la guerra que se espera no tanto de christianos como del Turco, a esto lo que todos los de acá juzgan es: que, pensando de hazer algun daño el Turco en la christiandad durante este tiempo, no solamente [no] seria el concilio dañoso, mas muy necessario, porque, hallándose todas las naciones y principes o sus embaxadores juntos en el dicbo concilio, podrian proveer más presto del remedio oportano; y tanto que paresce solo por la dicha cansa seria más que necessaria la convocación del dicho concilio, porque, en caso que el Turco entrasse con todo el poder que se teme, remedio de pocos principes no bastaria $y$, viniendo en el remedio toda la christiandad, se haria tan cumplido, que bastasse no solo para defender, más offender $\dot{a}$ los enemigos de nuestra santa fee. Y por esto no havria necessidad de deshazer el dicho concilio, porque dado en el la buena orden y recando que convernia, los anos se emplearian en el exercicio de las armas y los otros seguirian con su doctrina lo que convernia á la baena ordenación del dicho concilio, y assi los unos y los otros con el ayuda de nuestro Redemptor se emplearian en lo que a su santo servicio conviniesse. $Y$ este paresce que seria el verdadero camino para escusar todas las difficultades y qualquier otro gran inconveniente. 
Quanto a las benignas palabras llenas de toda confiança que de mi persona tiene, con la qual no obstante las alegaciones de los cardenales $V$. $S^{d}$ me remite este negocio como á persona que esta presente, para que eliga lo que más fuere al serricio de $\mathrm{N}$. Sor y de su santa fee, yo le beso sus santisimos pies $y$ digo, que me ha puesto mayor obligación de la que tenia, para mirar y pesar este negocio con aquella sana voluntad que an boen principe deve. $Y$ visto estos dias despues de haver recibido la carta de $V$. $S^{d}$ lo que se puede esperar destos principes lutheranos con quien al presente se negocia, que, anque con ellos se baya ganado harta tierra, es con presupuesto de lo que por estos otros principes le ha sido prometido del futuro concilio; $y$ consideradas las razones que de allá se alegan y lo que acá sobrello se ha platicado con toda aquella curiosidad $y$ diligencia que el caso requiere: mi parescer es, padre Beatissime, - por la obligación que devo á nuestro Redemptor y fermeza de la santa fee catholica $y$ voluntad que tengo á la exaltación de la santa sede apostolica y comodo y honrra de la persona de V. $\mathrm{S}^{\mathbf{d}}$, - que V. $B^{d}$ deve convocar el dicho concilio con aquel más breve tiempo que le paresciere conveniente; que, pues se juzga ser tan necessario á todos, nos va mucho en verlo ya acabado con aquel bueno $y$ santo fin que se espera. $Y$ podrá bien creer $V . S^{d} y$ tener de mi entera fee, que acá se porna toda entera y possible diligencia e industria, para que en este medio tiempo del dicho concilio estos principes y pueblos hayan de observar todo lo que con ellos fuere concertado con aquella obediencia que deven y primero solian tener á la santa sede apostolica; y paes en todo esto interviene el $\mathrm{R}^{\mathrm{mo}}$ cardenal Campegio su legado con la diligencia y pradencia que suele, el verá y será testimonio, que por nuestra parte no se omitirá cosa alguna para venir al effecto susodicho, y dará particular aviso a $V$. $S^{d}$ de todo lo que se soncluyere con los principes y pueblos y la forma que se da para les hazer observar todo en lo que vinieren y faeren obligados.

Quanto á lo que su $\mathrm{S}^{\mathrm{d}}$ scrive, que cerca de los abusos espera respnesta del legado y que embiará aquel remedio que convenga, assi por lo que conviene al bien del negocio como por complazer á su $\mathrm{M}^{\mathrm{d}}$-, que se le dan infinitas gracias $y$ que assi lo deve de hazer, porque aprovechará mucho para las cosas de acá. $Y$ pues el $R^{\text {mo }}$ legado desde el primer dia les ha prometido y pablicado, que tenia comissión y ampla facultad para lo hazer, que es bien que assi se effectue, $y$ que crea su $S^{d}$ que por su $M^{a}$ nunca le será demandada cosa que no convenga mucho 
demás del servicio de dios á la anthoridad de la sede apostolica. Y este es el punto más difficultoso que aqui hallamos $y$ en que más trabajamos, porque cierto esta nación estava muy apartada de la obediencia de la dicha sede apostolica. En lo demás que dé su $S^{d}$ fee á todo lo que el embaxador le dixere etc.

Nr. 5.

Karl V. an Juan Antonio Muxetula: Soll sofort nach Rom zaruckkehren and mit dem Papst uber die Verwendung der Trappen vor Florenz rerhandeln. 5-6000 Spanier and ein Teil der Italiener sollen entweder sofort nach Ungarn ziehen und auf gemeinsame Kosten der italienischen Staaten unterhalten werden, um gegen Turken oder Protestanten oder zam Schutze Italiens verwandt werden $z \mathfrak{n}$ können, oder in Asti, Parma and Piacenza uberwintern.

Augsburg 1530 September 23.

Simancas Generalarchiv, Estado 1557 fol. 96-98.

He visto lo que dezis de como os parece, que se devria entretener la mayor parte dese exército ó á lo menos la infanteria española y cavallos ligeros, y es todo muy bien y prudentemente dicho, y avemos holgado, que lo ayáis platicado con su $S^{\text {ad }}$ y de la buena voluntad que en su $B^{\text {tad }}$ para ello hablastes, que es la que de su may santa persona se espera. $Y$ por cierto que no avemos estado con poco cuidado mirando de la manera que agora estan las cosas de la christiandad, por que á no estar prevenidos sa $S^{\text {ad }}$ y yo podrian saceder grandes males; que por una parte lo de la fe en esta Alemaña esta tan malo como suele y con poca esperança de bien y, por ser agora tienpo de invierno y no tener el aparejo que es menester para usar de la fuerça, conviene dilatar algo la execución. Por otra parte esperase que el Tarco verna el año que viene. Por otra las cosas de Italia no estan tan acabadas de asegurar, como convernia á la paz y sosiego que su $S^{\text {ad }}$ y yo desseamos; desaziendo del todo ese exército, no solamente no avria con que remediar lo que se ofreciese, pero seria dar cabsa á que hiziesen lo que quiçá no dexan de pensar, y Florencia no ternia la seguridad. Que es menester tenerlo en Italia, querria yo que fuese en parte donde no se diese cabsa de ningund inconveniente ni suspición $y$ que á so $S^{\text {ad }}$ le agradase; pues enbiarlos al reino de Napoles, ya vos sabéis como esta aquel reino y que seria acabarlo de destrair y perder; y tanbien poderlo yo sostener todo, es imposible. 
Por lo qual confiando de vuestra prudencia diligencia y fidelidad y de la voluntad que sé que tenéis para serrirme, me ha parecido dar os trabajo que tornéis con toda la priesa que pudierdes á Roma á tratar y concertar esto con sa $\mathrm{S}^{\text {ad }}$, y entretanto que vos lo hazéis, escrivo á Hernando de Gonzaga y al duque de Melfi que aviendo despedido los Tadescos, como esta dicho, que retengan los Españoles en aquella comarca donde estan, sin pasar adelante, y esperen á lo que vos les escreviréis de nuestra parte que arréis concertado con su $\mathrm{S}^{\text {ad }}$. Encargo os mucho, que, de qualquier parte donde este correo os toparé, sin poner en ello escusa ni dilación, todas cosas dexadas, bolváis con toda diligencia y priesa a Roma y por virtud de mi carta de creencia que con la presente vos enbio digáis de mi parte á su $\mathrm{S}^{\text {ad, }}$, como me escrevistes la dicha platica que con su $B^{\text {tad }}$ pasastes, y lo bien que me ha parecido, y quanto conviene al bien de la christiandad y paz y quietud de Italia y seguridad de Florencia y bien sayo y mio, que sa $S^{\text {sd }}$ dé orden, como podamos entretener esos 5 ó 6 mill Españoles y alguna más parte del exército en Ungria; porque alli podrian mucho aprovechar para qualquier parte que el Turco quiera acometer; y siendo menester usar de fuerça en estas cosas de la fe, estarian para ello alli may à proposito, y ya podria ser, que fuesen cabsa, questos luteranos viniesen en lo que deven, de que agora estan may desviados; por lo qual, como he dicho, se entiende en dar algund sobreseimiento para ver lo que viniendo el buen tienpo se podrá hazer. Y an estando allí son bien à propósito para remediar qualquier cosa que se quisiese intentar para tarbar la paz y quietad de Italia, y siendo los efeotos para bien tan general de todos, mandandolo su $\mathrm{S}^{\text {ad, }}$ no creo, que avria ningano que se escusase de ayudar á ello. Y asi me parece que su $S^{\text {ad }}$ deve mirar la manera que en ello se terna, para que los potentados de Italia, pues es en bien general della, ayaden con lo que fuere menester, $y$ sa $S^{\text {ad }}$ por su parte haga lo mismo; que yo avré por bien de contribuir lo que su Sad mandaré.

Platicádgelo todo y suplicádle de mi parte, lo mire y considere may bien y vea lo que importa á nuestra fe y al bien de la christiandad y á la paz de Italia y seguridad de Florencia, en que tanbien aremos enbajado, y con la brevedad y buen efecto que es menester determine lo que en ello le parecerá, pues á anbos tanto nos va. La gente que deve ir de más de los dichos 5 mill Españoles, vealo su $S^{a d}$, y si le pareciere, deven ir algunos carallos ligeros y la cantidad de infantes italianos que 
sea buena, que mi intención es que aya alli en Lngria este namero de gente de Españoles y Italianos, porque para qualquiera de las necesidades que he dicho, con estar tan á la mano los Alemanes, brevemente se podrian hazer tan buen exército como quisiesemos y pudiesemos. Entenderéis en ello con la buena manera que soléis y con el cuidado y diligencia que tal negocio requiere, trabajando el buen efecto por todos los medios que pudieredes, avisándome may particularmente de lo que en ello pasaré, y para si conviniere que ros habléis de mi parte $\dot{a}$ algunos enbaxadores de sus potentados o otras personas, os enbio las cartas de creencia.

Si vieredes que despues de averlo vos may platicado $y$ porfiado á su $S^{\text {ad }}$ le pareciere dificaltoso, lo que no creo, pues tanto cunple á servicio de nuestro Señor $y$ anmento de su fe y bien de la christiandad y a su servicio $y$ al mio y á sostener la paz de ltalia $y$ tener segura á Florencia, platicádle otra manera para entretener este invierno los dichos 5 ó 6 mill Españoles para los dichos efectos. Y es, que sa $S^{\text {ad }}$ devia ver en que partes podrian estar; las que acd pareciere es: algunos en el condado de Aste, los otros repartidos en tierras de Parma y Plazencia 0 en otras de aquellas comarcas, con que no sea en el Modenes ni en Kezo, por estar como está aquello puesto en mis manos, y durante el compromiso seria dar cabsa de grand suspeción. Parece que estos 5 ó 6 mill Españoles se podrian entretener este invierno en las dichas partes con darles algana ayoda y no sueldo enteramente ...

$\mathrm{Si}$ en los dos medios que arriba he dicho no viniere su $S^{\text {ad, }}$ de que me pesaria mucho por lo que á anbos nos va, avisaréisme dello, para que yo vea lo que se hará de los dichos Españoles, y entretanto deténganse por donde agora estan, por que ir todos á Napoles seria acabarlo de destruir.

Tanbien parece que seria algand ayada, que como su $S^{\text {ad }}$ queria tener en Florencia mill Españoles, toriese 2 mill; y si quisiere que sean los 1 mill dellos á mi costa, podrianse pagar de Napoles; y en este caso se podrian todos mejor retener en Italia, paes la mayor parte de los que quedasen podria estar en Aste.

El medio postrero avéis de hablar, quando vieredes que su $S^{\text {ad }}$ no viene en lo primero, en lo qual avéis de insistir, quanto sea possible; ó si á vos os pareciere otros al dicho efecto, ponedlos delante y hazed en todo lo que de ros espero, avisandome particnlarmente de lo que pasaredes. 
Todo esto comunicaréis con el muy $\mathrm{R}^{\mathrm{do}}$ cardenal d'Osma $y$ con micer May, mi enbaxador, para que ellos por su parte ayaden lo que pudieren; que yo les escrivo solamente remitiéndome á lo que les diréis de mi parte.

De Augusta á 23 de setienbre $1530 \ldots$

$$
\text { Nr. } 6 .
$$

Karl V. an Garcia de Loaysa: Kann gegen die Ketzer nicht mit Gewalt vorgehen. Deshalb ist das Konzil das einzige Heilmittel.

Angsbarg 1530 Oktober 20.

Simancas Generalarchiv Estado 1558 fol. 61-62.

Todas vuestras letras de 25 de agosto, 11 del passado 1,2 del presente y las que avéis scripto al comendador mi secretario, he visto, y agradezco os mucho el trabajo, que tomáis en hazerlo tan continuamente y los buenos consejos que me dáis, los quales estimo en mucho y los recibo con la, buena voluntad y amor, [con] que sé que se dan, y pues as, es, no devéis cansar de continuarlo siempre y en ninguna cosa me podéis hazer más plazer.

Las ocupaciones de aqui han sido tan grandes y trabajosas, que me desculpan justamente de la dilación, que ha avido en responder á so $\mathbf{S}^{t}$ sobre lo del concilio; lo qual hago con don Pedro de la Cueva, que enbio á darle razon de lo que se ha hecho, que, como veréis por el despacho que lleva, es: arerse ronpido la negociación sin tomar ningand asiento, que estos herejes han estado tan obstinados, que ningand medio ha bastado ni aprovechado para atraerlos á apartarse de sus errores, ni menos à que sometiesen á la determinación, que se hiziese en el concilio con las limitaciones que dezis; que esto quisiera yo macho, si se padiera acabar. Bien veo, que, si oviera aparejo para forçarlos, justamente se pudiera emplear contra estos. Pero no lo ay de presente, ni yo tengo agora manera para ello, demás de ser el tienpo may contrario. El remedio que queda es: convocar el concilio, el qual yo creo que sa $\mathrm{S}^{\mathfrak{t}}$, conosciendo las causas que le serevimos y lo que importa al bien de la christiandad y el daño que esta claro que redundaria á toda ella, no lo negara, aunque aya algunos inconvenientes que lo osten. Bien sabemos que vos avéis de ayudar lo que pudieréis en ello, y assi os lo rogamos, que por todas las vias que vierdes que pueda aprovechar encamineis el buen efecto dello, aconsejando y hordenando á don Pedro lo que deviere hazer en todo.

Entretanto no se dexa de pensar y mirar en lo que 
converna hazerse en esto y de entender en tratar la eleción de rey de Romanos y en lo que más paresce que conviene ...

De Augusta 20. de otabre 1530.

Nr. 7.

Ans einem Briefe des Mignel Mai an Coros: Gegentuber den Kriegstreibereien der Kurialen baben sich die Gesandten an die kaiserlichen Instraktionen za halten, in denen ron einem EntschluB zam Kriege gegen die Protestanten nicht die Rede ist.

Rom 1530 Oktober 21.

Simaneas Generalarchiv, Estado 849 fol. 97.

... Estes elerigos, $\delta$ porque se les haia dicho $\dot{o}$ porque les sta bien, pensando por ay desviar el consilio, stan may puestos en que haga la guerra á los Lutheranos, y todos sus conseios andan en esto. $Y$ be oido que quieren scrivir al emperador, para que el scriva incitando á esto todos los principes christianos. Y porche yo no sé, si esto sta bien $\dot{a}$ su M., alomenos no sé ni se collige de mis cartas ni de las del Mngetola, que ste ahun determinando, si no de entretener el exército y colligir fuerzas, para aprovectarse del y dellas al buen tiempo, si fuere menester, ayer en presentia de Alonso Sanchis gelo dixe al Mugetola que no deviamos prendar al emperador, hasta que nos lo mandasse, sino tanto quanto se comprendia de sus cartas; y como su S. es cuerdo y agado, cayó en la cuenta y parescióle bien y dixó, que assi lo haria...

Nr. 8.

Aus einem Briefe des Rodrigo Niño, des Gesandten Karls V. in Venedig, an Migael Mai: Die Nachricht, daB der Papst Venedig um Subsidien fur die gegen die Lutheraner zu verwendenden Truppen bittet, hat nur Heiterkeit erregt.

Venedig 1530 Oktober 27.

Simancas Generalarchiv, Estado 1310 fol. 49.

El sabado passado vinó correo dessa corte á esta señoria con gran prissa. Ha se publicado que su $S^{d}$ pide ayuda á este stado de gente para contra los lattheranos. Estoy muy maravillado, que no tenga su $S^{d}$ aviso de que ay en esta tierra tanta parte de luttheranos que basta, para que se haya lo que se haze, que es: reirse muccho della; porque certifico á V. m. que no ay en toda esta cindad persona que no dessee el consilio, como si del oviesse de succeder á cada 
uno dellos un stado; y esto procede de que estan tan mal con su $S^{d}$, que no se podria dezir. Han scripto aqui de la corte, que so $M^{d}$ embia á don Pedro de la Cueva á sa $S^{d}$, á darle razón de lo que ha passado en la dieta y dezirle, que no se puede scusar el consilio. $Y$ estan tan alegres dello todos estos gentiles hombres venecianos, quanto se puede dezir, y loan al emperador N. S. por esto tanto, como por la paz que puso en Italia, que no lo puedo más encarescer. Supplico à V. m., me scriváis, si es verdad que sa $\mathrm{S}^{d}$ haya pedido a esta cindad esta ayuda; que, siendo assi, es el mayor donaire, que nunca vi: estar su $S^{d}$ tan mal avisado de lo de aquí, specialmente que se pablica que la pide, para que scuse el consilio . . .

\section{Nr. 9.}

Aus einem Briefe des Miguel Mai an den Kaiser: Der Papst will in den Breven an die italienischen Ftrsten von einem Krieg gegen die Protestanten nichts sagen. Abneigung der Venetianer gegen die Zahlung von Subsidien.

Rom 1530 Oktober 28.

Simancas Generalarchiv, Estado 849 fol. 101.

Á los 21 deste octabre serivi a V. M. Despues ha succedido, que, teniendo los breves que se han de embiar para los potentados de Italia concertados, á sn S. paresció, que no era bien empenyarse en dezir de hazer guerra á los Latheranos; porque yendo la copia dellos de mano en mano no les irritasse legando a ellos; y en esto paresce, que tiene razón, porque dize que lo quisiera hazer todo con acnerdo $y$ orden de V. M. ...

El enbarador de Venecianos en este dia ha dicho al papa que tiene cartas de Venecia, ahanque no de la senoria, que allá pensaran mucho en la contributión de la empresa contra Latheranos, porque en fin dizen, que es mover al Turcho, el qual despues del concierto de Bolonia siempre ha mirado mal sus cosas y rebufado á sus embaxadores, maiormente porque dizen que, ahunque entre los principes christianos haya paz, no les paresce que sten tan sin sospecha, como seria menester... 